\title{
Whole Body Findings Supplemental Qualifiers Dataset
}

National Cancer Institute

\section{Source}

National Cancer Institute. Whole Body Findings Supplemental Qualifiers Dataset. NCI

Thesaurus. Code C147269.

A dataset containing supplemental information, specifically non-standard variables, to parent records in the whole body findings domain. 